\title{
Prevalence and risk factors for the development of abdominal aortic calcification among the US population: NHANES study
}

Ebad Ur Rahman ${ }^{1}$, Muchi Ditah Chobufo², Fatima Farah ${ }^{3}$, Adee Elhamdani ${ }^{4}$, Arfaat Khan $^{5}$, Ellen A. Thompson ${ }^{6}$, Wilbert S. Aronow ${ }^{7}$, Mehiar El-Hamdani ${ }^{8}$

\author{
${ }^{1}$ Department of Internal Medicine, St Mary's Medical Center, Huntington, USA \\ ${ }^{2}$ Department of Internal Medicine, Interfaith Medical Center, Brooklyn NY, USA \\ ${ }^{3}$ Department of Medicine, Deccan College of Medical Sciences, Hyderabad, India \\ ${ }^{4}$ Allegheny Health Network, Pittsburgh, USA \\ ${ }^{5}$ Henry Ford Health System, Detroit, MI, USA \\ ${ }^{6}$ Department of Cardiology, Marshall University, Huntington, WV, USA \\ ${ }^{7}$ Department of Cardiology, Westchester Medical Center and New York Medical \\ College, Valhalla, NY, USA \\ ${ }^{8}$ Department of Cardiology, Marshall University, Huntington, WV, USA
}

Submitted: 15 December 2020

Accepted: 7 January 2021

Arch Med Sci Atheroscler Dis 2021; 6: e95-e101

DOI: https://doi.org/10.5114/amsad.2021.105527

Copyright (c) 2021 Termedia \& Banach

\begin{abstract}
Introduction: Abdominal aortic calcification (AAC) is an important marker of subclinical cardiovascular disease and its prognosis. Advanced age, hypertension, smoking, dyslipidemia, diabetes mellitus, and higher truncal fat are known markers of AAC in studies conducted around the world. However, literature for these risk factors and their co-occurrence is limited in the US. Material and methods: We used data from dual energy X-ray absorptiometry (Hologic, v4.0) to detect the occurrence of AAC in a sample population $(n=3140)$ of the NHANES survey using a computer-assisted interviewing system to assess the risk factors for AAC.

Results: We found the national prevalence of AAC in the US to be $28.8 \%$. After adjusting for confounders, persons with hypertension: $O R=1.66$ (95\% Cl: $1.30-2.13)$ and smokers: $\mathrm{OR}=1.63$ (95\% Cl: $1.24-2.14)$ were more likely to have AAC compared to their respective counterparts. Increasing age was positively associated with AAC: OR $=1.06$ (95\% Cl: 1.04-1.08). There was a statistically significant negative association between body mass in$\operatorname{dex}(\mathrm{BMI})$ and $\mathrm{AAC}$, more so in smokers than in non-smokers: $\mathrm{OR}=0.97$ (95\% Cl: 0.94-0.97). We did not observe any statistically significant association between diabetes and AAC.

Conclusions: Advanced age, smoking, and hypertension was associated with increased occurrence of AAC. Paradoxically, increasing BMI was inversely associated with AAC and there was no statistically significant association between total body and trunk fat percentages and AAC. To the best of our knowledge, this is the first study to establish the nationwide prevalence and associated factors in the US.
\end{abstract}

Key words: abdominal aortic calcification, prevalence, risk factors, NHANES database.

\author{
Corresponding author: \\ Dr. Ebad Ur Rahman \\ Department of Internal \\ Medicine \\ St Mary's Medical Center \\ $29001^{\text {st }}$ Avenue \\ 25702 Huntington, USA \\ E-mail: drebadmd@gmail.com
}




\section{Introduction}

Abdominal aortic calcification (AAC), a marker of subclinical cardiovascular disease [1], is associated with the extent and severity of coronary artery disease [2], stroke and heart failure [3]. The absence of AAC has a high negative predictive value to rule out coronary artery disease [4]. Prevalence of AAC varies widely among different groups. Prior studies have reported a prevalence of $31 \%$ in postmenopausal women with primary hyperparathyroidism and $13 \%$ in age-matched controls [5] and 70.6\% among patients with endstage renal disease (ESRD) and chronic kidney disease (CKD) [6].

Advanced age [7], hypertension [2], dyslipidemia [2], diabetes mellitus [2], higher visceral and subcutaneous fat content [8,9], and chronic smoking $[2,10]$ were highlighted as important risk factors for AAC. However, the pathophysiology of $A A C$ is different from most vessel disorders and not thoroughly elucidated [1]. Factors like phosphate accumulation, inflammation, hormonal changes, metabolic disorders, and oxidative stress have been implicated in the differentiation of vascular smooth muscle cells from osteoblasts leading to mineral deposition in the vessel wall [11]. Also, genetic predisposition for the development of AAC is well known [12]. A multifactorial interplay of these factors contributes in the development and progression of AAC.

Though AAC is an important marker of subclinical cardiovascular disease (CVD) and predictor of adverse outcomes, there is little dedicated documentation on the risk factors in the general population in the US. Given the dearth of literature on this, we set out to evaluate the national prevalence and associated factors of in persons 40 years of age and over in the US.

\section{Material and methods}

\section{Survey design}

The NHANES, conducted by the National Center for Health Statistics, collects nationally representative data on the health and nutritional status of the non-institutionalized US population. It utilizes a multistage probability sampling design and collects information from approximately 5,000 persons per year. Detail information on the survey design is available from the survey documentation [13]. Persons included in our analysis were 40 years and older with self-reported diagnosis of heart failure and valid entries for abdominal aortic calcifications.

\section{Data collection}

Survey participants were interviewed in their homes to ascertain demographic characteristics: age, gender, level of education, ethnicity, marital status, place of birth, health insurance, and smoking status using a Computer-Assisted Personal Interviewing system (i.e., interviewer-administered). Persons who reported having smoked at least 100 cigarettes in their lifetimes were classified as smokers. Body mass index (BMI) and waist circumference were obtained from trained health technicians using standardized protocols at mobile examination centers. Low-densty lipoprotein $(\mathrm{LDL})(\mathrm{md} / \mathrm{dl})$ was obtained using standard laboratory protocols. The family poverty index was calculated by dividing the total family income by the poverty threshold, as defined by the US census bureau, with adjustment for family size at the time of the interview [14]. Family poverty index ratio of $<1$ is considered "below poverty line" and $\geq 1$ is considered "at or above poverty line". Family PIR was grouped into three categories (PIR $<1.00$, PIR 1.00-2.99 and PIR $\geq 3.00$ ).

Although it is most commonly utilized to assess bone density, dual energy X-ray absorptiometry (DXA) imaging can also reliably establish the presence of AAC. DXA imaging has been found comparable to other popular diagnostic modalities in this regard. DXA scans were obtained by certified radiology technologists at mobile examination centers. Exclusion criteria for DXA imaging were self-reported pregnancy or positive urine pregnancy test; history of radiographic contrast use within seven days; body weight $\geq 450$ lbs; or a history of scoliosis with surgical rod implantation. There was a rigorous continuous monitoring that ensured that scan analysis was accurate and consistent. These consisted of quality control phantoms scans according to a predetermined schedule and daily Hologic Anthropomorphic Spine Phantom to ensure accurate calibration of the densitometer at the beginning of every day. Persons included in our study were $\geq 40$ years with complete data for AAC.

The AAC-24 scoring semi-quantitative technique was used for the evaluation of AAC according to previously published methods [15]. Persons with a score $\geq 1$ on the 24-point AAC scale were considered to have AAC. Body composition was analyzed using the Hologic software, APEX v4.0 (Hologic) followed by expert review conducted by the University of California, San Francisco (UCSF), Department of Radiology on $100 \%$ of analyzed participants for accuracy and consistency of results. All study questionnaires, exact question wording and response are available at no cost to the public [13].

\section{Statistical analysis}

Relevant questionnaire data files with variables of interest were merged with demographic information. Appropriate survey weights for dataset were applied to ensure estimates are representa- 
tive of the entire non-institutionalized US population in keeping with stipulated analytical guidelines [16]. Categorical variables are reported as proportions while continuous variables are reported as mean $(95 \% \mathrm{Cl})$. Associations were assessed using $\chi^{2}$ test for categorical variables or equality of means for continuous variables. Variables with $p$-values $\leq 0.10$ in unadjusted models were retained for multivariable logistic regression. After adjusting for confounding in multivariate models, predictive probabilities of $A A C$ by $B M I$ were generated and graphed using local polynomial smoothed plots. Identical analyses were also obtained for WC, total body fat percentage and trunk fat percentage. All variables were inspected using histogram and extreme outliers recorded to fall at upper or lower limits allow for better graphical representation. Analysis was done using STATA 16 and $p$-values less than 0.05 considered statistically significant.

\section{Results}

A total of 3140 participants underwent DXA imaging of which $28.8 \%$ had evidence of AAC. Table I shows the general characteristics of all study participants. In unadjusted models, older persons with a history of smoking, hypertension and diabetes were more likely to have AAC compared to their counterparts. AAC was also associated with the country of birth, race, marital status, poverty index ratio and health insurance status. Average BMI among persons with AAC was lower than among those without. There were no statistically significant associations between other variables and AAC status. Detailed results are shown in Table I.

After adjusting for confounders, persons with hypertension: $\mathrm{OR}=1.66(95 \% \mathrm{Cl}: 1.30-2.13)$ and ever smokers: $\mathrm{OR}=1.63(95 \% \mathrm{Cl}: 1.24-2.14)$ were more likely to have AAC compared to their respective counterparts. Increasing age was positively associated with AAC: OR $=1.06(95 \% \mathrm{Cl}$ : 1.04-1.08). There was a statistically significant negative association between $B M I$ and $A A C$, more so in smokers than in non-smokers (Figures 1, 5 and 6): OR = $0.97(95 \% \mathrm{Cl}: 0.94-0.97)$. We did not observe any statistically significant association between diabetes and AAC. Detailed results are shown in Table II.

Figures 1-6 show probability of having AAC across various variables viz: BMI, age, total body fat, waist circumference, and smoking history after controlling for confounders.

\section{Discussion}

Using nationally representative data, the national prevalence of AAC among persons 40 years and older was $28.8 \%$. Advanced age, smoking, hypertension and poverty were independently associated with AAC. Paradoxically, increasing BMI was inversely associated with AAC. There was no statistically significant association between total body and trunk fat percentages and AAC. To the best of our knowledge, this is the first study to establish the nationwide prevalence and associated factors in the US.

The strong association between advancing age and AAC was consistent with prior reports [5-7]. This could be attributed to the role of cumulative oxidative stress in the pathogenesis of AAC [17]. Oxidative stress in vascular smooth muscle cells leads to the activation of various signals such as Wnt, leading to osteogenic differentiation in the vascular walls [18]. Calcium deposition may further cause inflammation thus creating a vicious cycle leading to calcification of the vessel [19]. Also, increasing age is a risk factor in age-related diseases such as chronic kidney disease, cardiovascular diseases, neurodegenerative disorders, cancer etc., where the increased production of free radicals is known to play a major role in the pathogenesis and progression of AAC [20]. Unfortunately, we were unable to control for CKD which has been established as a significant risk factor for AAC.

Consistent with prior studies [21], hypertension was positively associated with AAC. However, debate remains on whether hypertension causes AAC or if AAC causes increased blood pressure due to arterial stiffness. An exact causal relationship cannot be drawn based on demographic studies alone. Smoking, which in itself is a risk factor for hypertension [22, 23], was also highly significantly correlated with the occurrence of AAC. This finding is consistent with various studies exploring the demographics of subjects with AAC [21, 24], dating as early as 1980 [25]. The mechanism of smoking with relation to $A A C$ is, however, not completely understood.

Interestingly, we found that increased $B M I$ is negatively correlated with the occurrence of AAC, indicating that a higher $\mathrm{BMI}$ may be protective from AAC. This is in agreement to previous studies which reported similar negative correlation [26, 27]. Though smokers were found to have a significantly higher odds of development of AAC, there was a rather protective association among smokers with increasing BMI and AAC. This runs in contrary to the observation that obesity associated with chronic smoking is known to significantly enhance cardiovascular mortality [28]. To the best of our knowledge, there are no studies examining this synergistic effect of obesity and chronic smoking for protection from AAC or vascular calcification. Therefore, future studies focusing on this synergistic effect may shed light on the pathophysiology of AAC in general. 
Ebad Ur Rahman, Muchi Ditah Chobufo, Fatima Farah, Adee Elhamdani, Arfaat Khan, Ellen A. Thompson, Wilbert S. Aronow, Mehiar El-Hamdani

Table I. Participant characteristics

\begin{tabular}{|c|c|c|c|c|}
\hline Variable & Percentage (\%) & $\begin{array}{c}\text { AAC+ } \\
(28.83 \% \text { of all subjects })\end{array}$ & $\begin{array}{c}\text { AAC- } \\
\text { (71.17\% of all subjects) }\end{array}$ & $P$-value \\
\hline Age & $57.38(56.75-58.01)$ & $63.53(61.82-65.25)$ & $54.89(54.36-55.41)$ & $<0.001$ \\
\hline $\mathrm{BMI}$ & $28.53(28.48-28.90)$ & $27.79(27.33-28.25)$ & $28.84(28.33-29.20)$ & $<0.001$ \\
\hline Waist circumference & 39.29 (39.00-39.59) & $39.13(38.67-39.59)$ & 39.54 (39.07-39.64) & 0.276 \\
\hline LDL & $115.58(113.68-117.47)$ & $115.30(113.17-117.44)$ & $115.70(112.93-118.46)$ & 0.833 \\
\hline Total fat percentage & $33.63(33.02-34.24)$ & $32.86(31.76-33.95)$ & $33.81(33.25-34.37)$ & 0.055 \\
\hline Trunk fat percentage & $32.86(32.22-33.50)$ & $32.39(31.23-33.55)$ & $32.97(32.38-33.56)$ & 0.226 \\
\hline Sex: & & & & 0.742 \\
\hline Male & 48.08 & 48.61 & 47.86 & \\
\hline Female & 51.92 & 51.39 & 52.14 & \\
\hline Race: & & & & 0.024 \\
\hline Hispanic & 11.63 & 8.64 & 12.84 & \\
\hline Non-Hispanic black & 10.94 & 8.11 & 10.94 & \\
\hline Non-Hispanic white & 68.94 & 76.10 & 68.94 & \\
\hline Other & 7.28 & 7.15 & 7.28 & \\
\hline Hypertension: & & & & $<0.001$ \\
\hline Yes & 36.19 & 49.98 & 30.60 & \\
\hline No & 68.31 & 50.02 & 69.40 & \\
\hline Diabetes mellitus: & & & & 0.003 \\
\hline Yes & 11.50 & 16.64 & 12.98 & \\
\hline No & 88.50 & 83.36 & 87.02 & \\
\hline Smoking history: & & & & 0.001 \\
\hline Yes & 46.00 & 55.35 & 42.22 & \\
\hline No & 54.00 & 44.65 & 57.78 & \\
\hline Educational attainment: & & & & 0.665 \\
\hline No high school diploma & 5.11 & 5.49 & 4.95 & \\
\hline $\begin{array}{l}\text { High school degree or } \\
\text { equivalent }\end{array}$ & 9.94 & 11.12 & 9.94 & \\
\hline College degree & 85.11 & 83.39 & 85.11 & \\
\hline Marital status: & & & & $<0.001$ \\
\hline Never married & 6.97 & 5.22 & 7.68 & \\
\hline Married/living together & 68.51 & 62.88 & 70.80 & \\
\hline $\begin{array}{l}\text { Divorced/widowed/ } \\
\text { separated }\end{array}$ & 24.52 & 31.90 & 21.53 & \\
\hline Birthplace: & & & & 0.015 \\
\hline United States & 82.63 & 86.68 & 82.63 & \\
\hline $\begin{array}{l}\text { Outside the United } \\
\text { States }\end{array}$ & 17.37 & 13.32 & 17.37 & \\
\hline Insurance status: & & & & 0.008 \\
\hline Insured & 87.06 & 90.46 & 85.68 & \\
\hline Uninsured & 12.94 & 9.54 & 14.32 & \\
\hline Poverty index ratio: & & & & 0.002 \\
\hline$<1$ & 11.05 & 11.42 & 10.90 & \\
\hline$\geq 1$ and $<3$ & 29.82 & 36.78 & 26.99 & \\
\hline$\geq 3$ & 59.14 & 51.80 & 62.11 & \\
\hline
\end{tabular}

*Statistical significance. AAC - abdominal aortic calcification. Poverty index ratio defined as total household income divided by poverty threshold. Values represent within column percentages. 


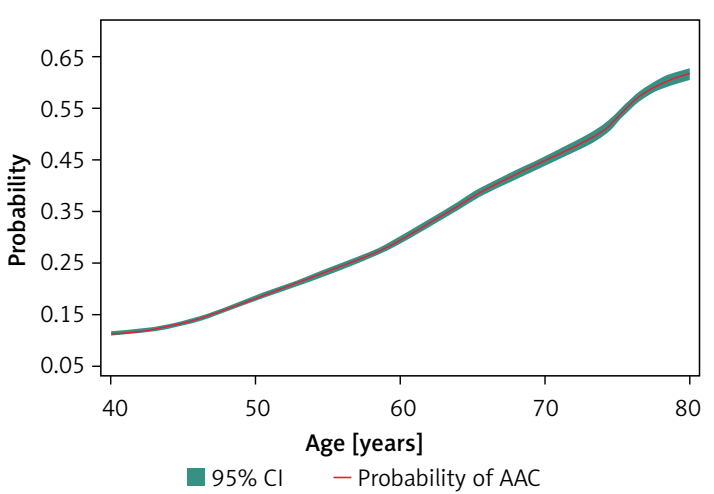

Figure 1. Effect of age on development of AAC

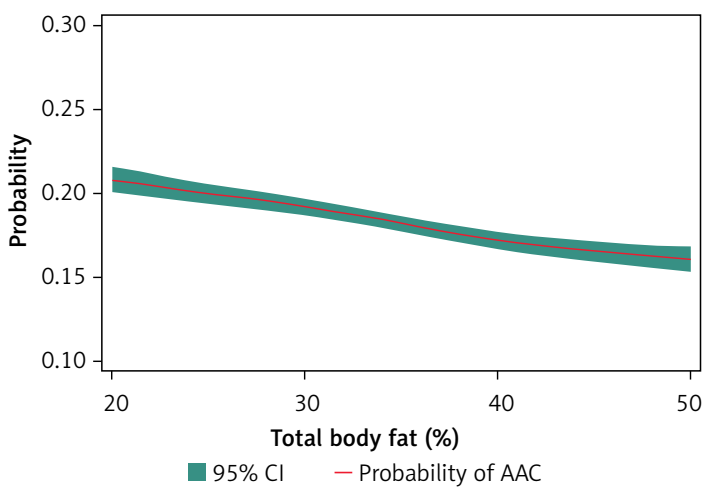

Figure 3. Effect of total body fat on development of AAC

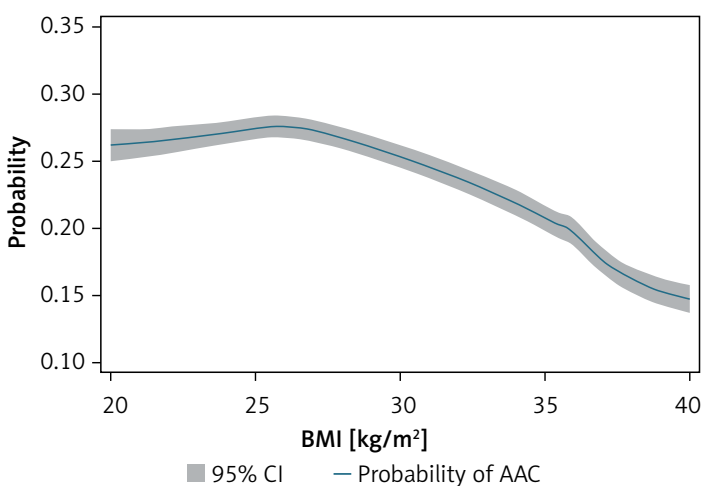

Figure 5. Effect of $B M I$ on $A A C$ in smokers

We also noted that there is no effect of increased waist circumference or trunk fat on occurrence of AAC, while there was a marginally inverse effect of total fat percentage, albeit not statistically significant. Dyslipidemia, which is an established consequence of obesity, has often been considered as a risk factor for vascular calcification and as its accelerant, especially in AAC [5, $18,29]$. Although the exact mechanism is not well known, oxidation of lipids may play a role in the pathogenesis of vascular calcification [17]. Also, different fat compartments have its own effect on development and progression of vasculopathy. This was highlighted by the findings in the Framingham heart study where it was found that in-

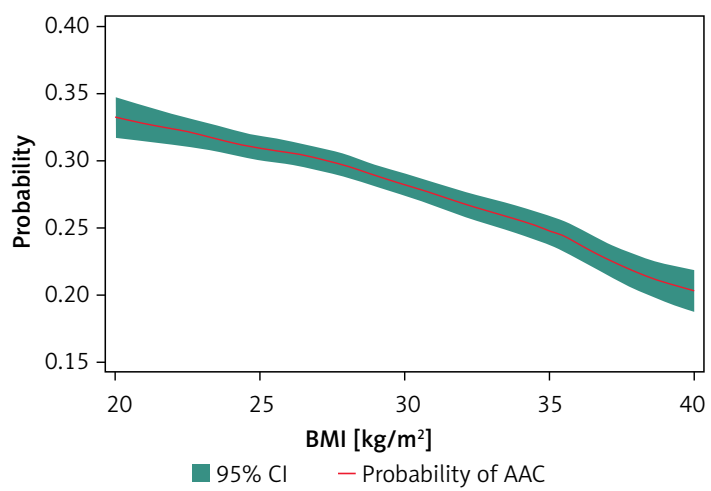

Figure 2. Effect of $B M I$ on development of AAC

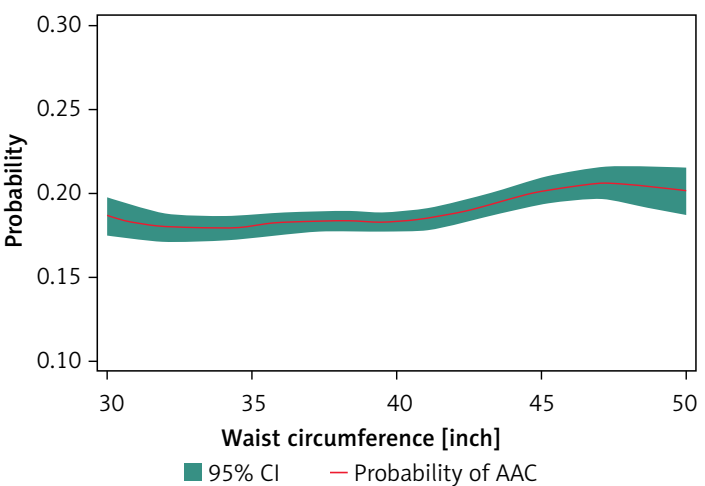

Figure 4. Effect of waist circumference on AAC

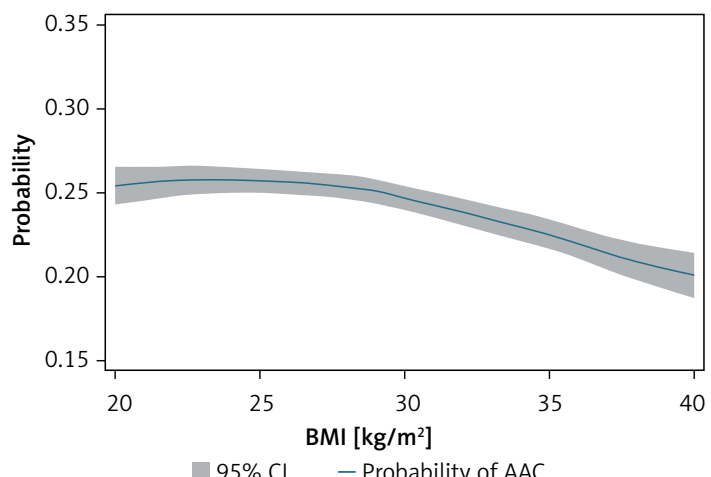

Figure 6. Effect of $B M I$ on $A A C$ in non-smokers

creased peri-aortic fat mass was associated with both coronary and abdominal aortic calcification [30]. Also, subcutaneous and visceral fat mass have different effects in various metabolic disorders and this has been demonstrated in abdominal aortic calcification as well [8, 26, 31].

Diabetes, an established risk factor for atherosclerosis in many other vascular beds was not associated with AAC. This is contrary to findings by Echouffo-Tcheugui et al. [32] who reported a positive association between AAC and diabetes. However, their study was limited to African Americans only. Whether this is a spurious finding or another paradoxical observation as it is the case with obesity remains an unanswered question. This may 
Ebad Ur Rahman, Muchi Ditah Chobufo, Fatima Farah, Adee Elhamdani, Arfaat Khan, Ellen A. Thompson, Wilbert S. Aronow, Mehiar El-Hamdani

Table II. Factors independently associated with AAC prevalence (multivariate logistic regression comprising all variables with $p<0.10$ in univariate models with AAC)

\begin{tabular}{|c|c|c|c|}
\hline Variable & Categories & Odds ratio & $P$-value \\
\hline Body mass index & & $0.97(0.94-0.97)$ & $<0.001$ \\
\hline Age & & $1.06(1.04-1.08)$ & $<0.001$ \\
\hline \multirow[t]{4}{*}{ Race: } & NH Whites & 1 & \\
\hline & Hispanics & $1.05(0.65-1.67)$ & 0.84 \\
\hline & Blacks & $0.73(0.42-1.28)$ & 0.25 \\
\hline & Others & $1.34(0.95-1.89)$ & 0.09 \\
\hline \multirow[t]{3}{*}{ Marital status: } & Married & 1 & \\
\hline & Divorce/separated & $1.18(0.89-1.57)$ & 0.221 \\
\hline & Never married & $0.82(0.54-1.26)$ & 0.341 \\
\hline \multirow[t]{2}{*}{ Country of birth: } & US & & \\
\hline & Non-US & $0.70(0.46-1.08)$ & 0.097 \\
\hline \multirow[t]{2}{*}{ Insurance: } & Yes & & \\
\hline & No & $1.00(0.68-1.48)$ & 1 \\
\hline \multirow[t]{3}{*}{ Poverty index ratio: } & $<1$ & 1 & \\
\hline & 1 to 3 & $1.10(0.80-1.52)$ & 0.537 \\
\hline & $>3$ & $0.79(0.51-1.23)$ & 0.272 \\
\hline \multirow[t]{2}{*}{ HTN: } & No & 1 & \\
\hline & Yes & $1.66(1.30-2.13)$ & 0.001 \\
\hline \multirow[t]{2}{*}{ Diabetes: } & No & 1 & \\
\hline & Yes & $1.14(0.89-1.45)$ & 0.279 \\
\hline \multirow[t]{2}{*}{ Smoking: } & No & & \\
\hline & Yes & $1.63(1.24-2.14)$ & 0.002 \\
\hline
\end{tabular}

also suggest that while all vascular beds are prone to calcifications, the exact mechanisms as well as risk factors leading to their development.

Being a cross-sectional study, causal inferences cannot be deduced. Also, AAC has not been consistently evaluated over many survey cycles to have allowed for data pooling to increase sample size and statistical power for stable and reliable estimates. Furthermore, we were unable to adjust for CKD status, a condition with prevalent AAC. Notwithstanding these limitations, we are the first, to our knowledge, to report nationwide prevalence and associated factors of AAC in the US.

In conclusion, in the present study, we found that various factors that increased or decreased the probability for occurrence of AAC. Examining the complex pathogenesis involved in the development and progression of AAC was beyond the scope of this paper. However, further studies are needed to understand the synergistic effect of obesity and smoking along with the functions of different adipose tissue compartments in the pathophysiology of AAC.

\section{Acknowledgments}

Muchi Ditah Chobufo and Ebad Ur Rahman have contributed equally to this study.

\section{Conflict of interest}

The authors declare no conflict of interest.

\section{References}

1. Frink RJ. Calcification: A Physiologic Defense. Inflammatory Atherosclerosis: Characteristics of the Injurious Agent. Frink RJ (ed.). Heart Research Foundation, Sacramento (CA) 2002.

2. Churchill TW, Rasania SP, Rafeek H, et al. Ascending and descending thoracic aorta calcification in type 2 diabetes mellitus. J Cardiovasc Comput Tomogr 2015; 9 : 373-81.

3. Szulc P. Abdominal aortic calcification: a reappraisal of epidemiological and pathophysiological data. Bone 2016; 84: 25-37.

4. Zweig BM, Sheth M, Simpson S, Al-Mallah MH. Association of abdominal aortic calcium with coronary artery calcium and obstructive coronary artery disease: a pilot study. Int J Cardiovasc Imaging 2012; 28: 399-404.

5. Du KE, Kim JS, Kim SS, et al. Association of abdominal aortic calcification with lifestyle and risk factors of cardiovascular disease. Korean J Fam Med 2013; 34: 213-20.

6. Lumlertgul D, Kantachuvesiri S, Apichaiyingyurd S, et al. Prevalence of and predictive factor for abdominal aortic calcification in thai chronic kidney disease patients. Ther Apher Dial 2017; 21: 611-9.

7. Rodondi N, Taylor BC, Bauer DC, et al. Association between aortic calcification and total and cardiovascular mortality in older women. J Intern Med 2007; 261: 238-44. 
8. Goldenberg L, Saliba W, Hayeq H, Hasadia R, Zeina AR The impact of abdominal fat on abdominal aorta calcification measured on non-enhanced CT. Medicine 2018; 97: e13233.

9. Jensky NE, Criqui MH, Wright CM, Wassel CL, Alcaraz JE, Allison MA. The association between abdominal body composition and vascular calcification. Obesity 2011 19: 2418-24.

10. Tsai JP, Jan YT, Yun CH, et al. Associations of cigarette smoking and burden of thoracic aortic calcification in asymptomatic individuals: a dose-response relationship. PLoS One 2020; 15: e0227680.

11. Alves RDAM, Eijken M, van de Peppel J, van Leeuwen JPTM. Calcifying vascular smooth muscle cells and osteoblasts: Independent cell types exhibiting extracellular matrix and biomineralization-related mimicries. BMC Genomics 2014; 15: 965.

12. Qiao JH, Xie PZ, Fishbein MC, et al. Pathology of atheromatous lesions in inbred and genetically engineered mice genetic: determination of arterial calcification. Arterioscler Thromb Vasc Biol 1994; 14: 133-40.

13. NHANES Questionnaires, Datasets, and Related Documentation.

14. Bureau UC. How the Census Bureau Measures Poverty. Available at: https://www.census.gov/topics/incomepoverty/poverty/guidance/poverty-measures.html

15. Kauppila LI, Polak JF, Cupples LA, Hannan MT, Kiel DP, Wilson PWF. New indices to classify location, severity and progression of calcific lesions in the abdominal aorta: a 25-year follow-up study. Atherosclerosis 1997; 132: 245-50.

16. NHANES Survey Methods and Analytic Guidelines.

17. Evrard S, Delanaye P, Kamel S, et al. Vascular calcification: from pathophysiology to biomarkers. Clin Chim Acta 2015; 438: 401-14

18. Shao JS, Cheng SL, Pingsterhaus JM, Charlton-Kachigian N, Loewy AP, Towler DA. Msx2 promotes cardiovascular calcification by activating paracrine Wnt signals. J Clin Invest 2005; 115: 1210-20.

19. Shanahan CM. Inflammation ushers in calcification: a cycle of damage and protection? Circulation 2007; 116: 2782-5.

20. Liguori I, Russo G, Curcio F, et al. Oxidative stress, aging, and diseases. Clin Interv Aging 2018; 13: 757-72.

21. Jayalath RW, Mangan SH, Golledge J. Aortic calcification. Eur J Vasc Endovasc Surg 2005; 30: 476-88.

22. Virdis A, Giannarelli C, Fritsch Neves M, Taddei S, Ghiadoni L. Cigarette smoking and hypertension. Curr Pharm Des 2010; 16: 2518-25.

23. Gao K, Shi X, Wang W. The life-course impact of smoking on hypertension, myocardial infarction and respiratory diseases. Sci Rep 2017; 7: 4330.

24. Jiang $C Q$, Lao $X Q$, Yin $P$, et al. Smoking, smoking cessation and aortic arch calcification in older Chinese: the Guangzhou Biobank Cohort Study. Atherosclerosis 2009; 202: 529-34.

25. Auerbach O, Garfinkel L. Atherosclerosis and aneurysm of aorta in relation to smoking habits and age. Chest 1980; 78: 805-9.

26. Fox CS, Hwang SJ, Massaro JM, et al. Relation of subcutaneous and visceral adipose tissue to coronary and abdominal aortic calcium (from the Framingham Heart Study). Am J Cardiol 2009; 104: 543-7.

27. Tankó LB, Bagger YZ, Alexandersen P, Larsen PJ, Christiansen C. Central and peripheral fat mass have contrasting effect on the progression of aortic calcification in postmenopausal women. Eur Heart J 2003; 24: 1531-7.
28. Freedman DM, Sigurdson AJ, Rajaraman P, Doody MM, Linet MS, Ron E. The mortality risk of smoking and obesity combined. Am J Prev Med 2006; 31: 355-62.

29. Huang JW, Lien YC, Yang CY, et al. Osteoprotegerin, inflammation and dyslipidemia are associated with abdominal aortic calcification in non-diabetic patients on peritoneal dialysis. Nutr Metab Cardiovasc Dis 2014; 24: 236-42.

30. Lehman SJ, Massaro JM, Schlett CL, O'Donnell CJ, Hoffmann U, Fox CS. Peri-aortic fat, cardiovascular disease risk factors, and aortic calcification: The Framingham Heart Study. Atherosclerosis 2010; 210: 656-61.

31. Golledge J, Jayalath R, Oliver L, Parr A, Schurgers L, Clancy P. Relationship between CT anthropometric measurements, adipokines and abdominal aortic calcification. Atherosclerosis 2008; 197: 428-34.

32. Echouffo-Tcheugui JB, Allison M, Kalyani RR, Sims M, Bertoni AG, Golden SH. Abdominal aortic calcification among individuals with and without diabetes: the Jackson Heart Study. Diabetes Care 2017; 40: e106-7. 